\title{
LONG-MEMORY FORECASTING OF U.S. MONETARY INDICES
}

\author{
John Barkoulas \\ Department of Finance \& Quantitative Analysis \\ Georgia Southern University \\ Statesboro, GA 30460, USA \\ Tel. (912) 871-1838, Fax (912) 871-1835 \\ Email: jbarkoul@georgiasouthern.edu
}

\author{
Christopher F. Baum* \\ Department of Economics \\ Boston College \\ Chestnut Hill, MA 02467 \\ Email: baum@bc.edu
}

Running head: Long-memory forecasting of U.S. monetary indices

\begin{abstract}
Several studies have tested for long-range dependence in macroeconomic and financial time series but very few have assessed the usefulness of long-memory models as forecast generating mechanisms. This study tests for fractional differencing in the U.S. monetary indices (simple sum and divisia) and compares the out-of-sample fractional forecasts to benchmark forecasts. The long-memory parameter is estimated using Robinson's Gaussian semiparametric and multivariate log-periodogram methods. The evidence amply suggests that the monetary series possess a fractional order between one and two. Fractional outof-sample forecasts are consistently more accurate (with the exception of the M3 series) than benchmark autoregressive forecasts but the forecasting gains are not generally statistically significant. In terms of forecast encompassing, the fractional model encompasses the autoregressive model for the divisia series but neither model encompasses the other for the simple sum series.
\end{abstract}

Keywords: long memory, ARFIMA model, macroeconomic forecasting.

* Corresponding author: tel +1-617-552-3673, fax +1-617-552-2308 


\section{LONG-MEMORY FORECASTING OF U.S. MONETARY INDICES}

\section{Introduction}

In this study we investigate the presence of long memory and its usefulness as a forecast generating mechanism for the U.S. monetary aggregates. The fractional differencing model employed is the autoregressive fractionally integrated moving average (ARFIMA) type introduced by Granger and Joyeux (1980), Hosking (1981), and Geweke and Porter-Hudak (1983). Regarding macroeconomic time series, evidence of fractional integration has been found in output series (Diebold and Rudebusch (1989), Sowell (1992)), consumption (Diebold and Rudebusch (1991)), and inflation rates (Baillie, Chung, and Tieslau (1996), Hassler and Wolters (1995), Baum, Barkoulas, and Caglayan (1999)). Porter-Hudak (1990) reported evidence of long memory in simple sum monetary aggregates while Barkoulas, Baum, and Caglayan (1999) extended similar findings to components of simple-sum monetary aggregates, divisia monetary indices, the monetary base, and money multipliers.

Despite the evidence of long memory in macroeconomic series, there are few applied studies in the literature regarding the predictive ability of ARFIMA models. ${ }^{1}$ Such forecasting evaluation would serve as a test of model adequacy, in discriminating among competing economic hypotheses, and be useful in guiding policy-making decisions (see Fildes and Stekler (2002) and references therein for a recent review of issues regarding macroeconomic forecasting). Granger and

1 Guegman (1994) points out that, despite the fundamental interest in forecasting, very few studies related to ARFIMA forecasts have been implemented. 
Joyeux (1980) discuss the forecasting potential of fractional models. Cheung (1993) finds that ARFIMA-generated forecasts fail to improve upon random-walk forecasts for foreign exchange rates. Lardic and Mignon (1996) however provide evidence that fractional forecasts have better predictive accuracy in the short term (relative to random-walk and structural model forecasts) for three major currencies. Franses and Ooms (1997) report that ARFIMA models fail to generate superior forecasts over competing models for the U.K. inflation rate. Through extensive Monte Carlo analysis, Ray (1993a) and Crato and Ray (1996) find that simple ARMA models generally outperform or provide competitive forecasts compared to ARFIMA models. On the other hand, Ray (1993b) establishes that, by certain criteria, a fractional model provides more accurate forecasts than benchmark models for IBM product revenues. Barkoulas and Baum (1997) show that long-memory forecasts result in dramatic improvements in forecasting accuracy, especially over longer horizons, relative to rival models for several Eurocurrency deposit rates.

In this paper we investigate the ability of ARFIMA-based forecasts to outperform benchmark linear forecasts on an out-of-sample basis for seasonally adjusted U.S. simple sum and divisia monetary indices. Using Robinson's $(1995 a, b)$ Gaussian semiparametic and multivariate log-periodogram estimation methods, we find that the monetary indices are fractionally integrated processes. We subsequently generate genuine out-of-sample fractional forecasts and compare their accuracy to linear autoregressive forecasts. The statistical significance of forecasting accuracy of competing forecasts is evaluated using the Diebold-Mariano (1995) test. We also employ the forecast encompassing testing approach for the out-of-sample competing forecasts. We find that the ARFIMA 
model provides consistently more accurate point forecasts compared to the autoregressive model for the monetary indices (with the exception of the M3 series), but the superiority is not statistically significant in general. The fractional model appears to encompass the autoregressive model for the divisia indices but neither model is superior in terms of forecast encompassing for the simple sum indices. Only rarely are fractional forecasts inferior to autoregressive ones. The evidence is encouraging for the predictive ability of the nonlinear fractional model for these monetary series.

The plan of the paper is as follows. Section 2 presents the fractional model and the estimation method for the fractional-differencing parameter. Data and empirical results are reported in Section 3. We conclude in Section 4 with a summary and implications of our findings.

\section{Fractionally Differenced Modeling}

The model of an autoregressive fractionally integrated moving average process of order $(p, d, q)$, denoted by ARFIMA $(p, d, q)$, with mean $\mu$, may be written using operator notation as

$$
\Phi(L)(1-L)^{d}\left(y_{t}-\mu\right)=\Theta(L) u_{t}, \quad u_{t} \sim \text { i.i.d. }\left(0, \sigma_{u}^{2}\right)
$$

where $L$ is the backward-shift operator, $\Phi(L)=1-\phi_{1} L-\ldots-\phi_{p} L^{p}$, $\Theta(L)=1+\vartheta_{1} L+\ldots+\vartheta_{p} L^{p}$, and $(1-L)^{d}$ is the fractional differencing. The parameter $d$ is allowed to assume any real value. The arbitrary restriction of $d$ 
to integer values gives rise to the standard autoregressive integrated moving average (ARIMA) model. The stochastic process $y_{t}$ is both stationary and invertible if all roots of $\Phi(L)$ and $\Theta(L)$ lie outside the unit circle and $\quad|d|<0.5$. The process is said to exhibit long-memory behavior for $d \in(0,1)$. For $d \in[0.5,1)$, $y_{t}$ is nonstationary (having an infinite variance) but it is mean reverting.

Robinson (1995a) proposes a Gaussian semiparametric estimator, GS hereafter, of the self-similarity parameter $H$. Assume that the spectral density of the time series, denoted by $f(\cdot)$, behaves as

$$
f(\xi) \sim G \xi^{1-2 H} \text { as } \xi \rightarrow 0^{+}
$$

for $G \in(0, \infty)$ and $H \in(0,1)$. The self-similarity parameter $H$ relates to the longmemory parameter $d$ by $H=d+1 / 2$. The estimate of $H$, denoted by $\hat{H}$, is obtained through minimization of the function

$$
R(H)=\ln \hat{G}(H)-(2 H-1) \frac{1}{v} \sum_{\lambda=1}^{v} \ln \xi_{\lambda}
$$

with respect to $H$, where $\hat{G}(H)=\frac{1}{v} \sum_{\lambda=1}^{v} \xi_{\lambda}^{2 H-1} I\left(\xi_{\lambda}\right)$ and $v=g(T)<T$ is the number of Fourier frequencies included in the estimation. The GS estimator is $v^{1 / 2}$ - consistent with the variance of the limiting distribution free of nuisance parameters and equal to $1 / 4 v$. 
We also estimate the fractional parameter using Robinson's (1995b) multivariate formulation of the log-periodogram regression estimator. Let $Y_{t}$ represent a $M$-dimensional vector with $m^{\text {th }}$ element $Y_{m t}, m=1, \ldots, M$. Assume that $Y_{t}$ has a spectral density matrix $\int_{-\pi}^{\pi} e^{i j \xi} f(\xi) d \xi$, with $(m, \lambda)$ element denoted by $f_{m h}(\xi)$. The periodogram of $Y_{m t}$ is denoted as

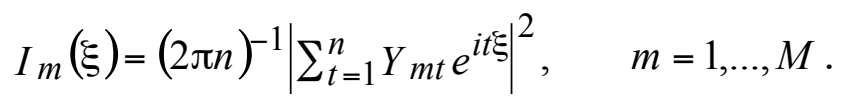

Define $X_{m \lambda}=\log I_{m}\left(\xi_{\lambda}\right)$. The least squares estimate of $\quad G=\left(G_{1}, \ldots G_{M}\right)^{\prime}$ and $d=\left(d_{1}, \ldots d_{M}\right)^{\prime}$ are given by

$$
\left[\begin{array}{l}
\widetilde{G} \\
\tilde{d}
\end{array}\right]=\operatorname{vec}\left\{X^{\prime} Z\left(Z^{\prime} Z\right)^{-1}\right\}
$$

where $Z=\left(Z_{1}, \ldots Z_{M}\right)^{\prime}, Z_{\lambda}=\left(1,-2 \log \xi_{\lambda}\right)^{\prime}, X=\left(X_{1}, \ldots X_{M}\right)$, and $X v=\left(X_{m, 1}, \ldots X_{m, v}\right)^{\prime}$ for $v$ periodogram ordinates. Standard errors for $d_{m}$ estimates and for a test of the restriction that two or more of the $d_{m}$ are equal may be derived from the estimated covariance matrix of the least squares coefficients.

\section{Empirical Results}

We perform the analysis on monthly, seasonally adjusted U.S. simple sum (SM1, SM2, SM3, and SL) and divisia monetary aggregates (DM1, DM2, DM3, and DL) covering the period 1959:1-2002:12 (the SL and DL aggregates span the 
period until 1998:9 after which they were discontinued). The series are obtained from the Federal Reserve Bank of St Louis' FRED database. The sample period 1959:1-1990:12 is used for in-sample estimation (training data set) with the remainder of the sample reserved for out-of-sample forecasting purposes (validation data set).

Figures 1 and 2 graph the first 120 autocorrelation coefficients for the growth rates of the simple sum and divisia indices, respectively. The autocorrelations exhibit a clear pattern of persistence and slow decay which is typical of a long-memory process. The M1 measure of money appears to display a lower degree of persistence relative to the broader measures.

Table 1 reports the GS estimates of the fractional differencing parameter $d$ for the growth rates of the monetary series over the in-sample period (the integration order for the level series is given by $d+1)$. The fractional order estimates are fairly stable across bandwidth choices. Strong evidence of a fractional order between one and two is found in all monetary aggregates.

Robinson's LPR test results are presented in Table 2, yielding a vector of $d$ estimates, which may be tested for their joint equality via a standard $\quad F$ statistic. Consistent evidence of fractional differencing is detected in all simple sum and divisia monetary series. Except for the shorter bandwidth choices, the $F$ test rejects the hypothesis that all simple sum (or divisia) series share the same order of integration. It is apparent that the $d$ estimate for the narrower measure of money, M1, is significantly lower than that of the broader money measures. In a panel including only the $\mathrm{M} 2, \mathrm{M} 3$, and $\mathrm{L}$ money series, the $F$ test fails to reject the hypothesis that the broader aggregates share a common differencing parameter for both simple sum and divisia indices. 
The Robinson LPR test results largely corroborate the GS findings. The order of integration for the growth rates of simple sum and divisia monetary series is clearly distinguishable from both zero and unity. The growth rates of the monetary series are characterized by hyperbolically declining cumulative impulse response weights and unbounded spectral densities at the zero frequency.

The discovery of a fractional integration order suggests possibilities for constructing nonlinear econometric models for improved forecasting performance of the monetary series. The ARFIMA process represents a flexible and parsimonious way to model both the short and long term dynamic properties of the series. We proceed to assess the out-of-sample forecasting effectiveness of the ARFIMA model relative to the rival linear autoregressive (AR) model. Comparing the predictive distribution of future observations to that of the realized data is a good way of model validation.

Given the GS estimates of $d$, we approximate the short-run series dynamics by fitting an AR model to the fractionally differenced series using BoxJenkins methods. ${ }^{23}$ A question arises as to the asymptotic properties of the AR parameter estimates in the second stage. Conditioning on the $d$ estimate obtained in the first stage, Wright (1995) shows that the $\operatorname{AR}(p)$ fitted by the YuleWalker procedure to the $d$-differenced series inherit the $T^{\delta}$-consistency of the

2 All fractional forecasts are based on the GS estimates of the long-memory parameter. More specifically, we condition on the average (across bandwidths) GS $d$ estimate. The results below are not materially altered if we condition on the lower or higher GS $d$ estimate. It must be noted that the various $d$ estimates are within sampling error for each series for both GS and Robinson's LPR estimation methods.

3 The AR order is determined using the Akaike information criterion (AIC) allowing for a maximum lag length of order 12. Given the optimal choice of lag length, the estimated residual vector is tested for serial correlation up to order 24 . If the residual vector is serially correlated, the lag length is increased until a serially uncorrelated residual vector is obtained. 
semiparametric estimate of $d$. We forecast the monetary series by casting the fitted fractional-AR model in infinite autoregressive form, truncating the infinite autoregression at the beginning of the sample (thus setting data points before the sample period equal to zero), and applying Wold's chain rule. A similar procedure was followed by Diebold and Lindner (1996) to forecast the real interest rate and Ray (1993b) to forecast IBM product revenues.

The long memory forecasts are compared to those generated by a linear AR model. ${ }^{4}$ Observations corresponding to the sample period starting in 1991:1 until the end of the sample are our test set (post-prediction interval). ${ }^{5} \mathrm{We}$ consider 1-, 2-, 3-, 4-, 5-, 6-, 7-, 8-, 9-, 10-, 11-, 12-, 15-, 18-, 21-, and 24-months ahead forecasting horizons. These forecasts are truly ex ante, or dynamic, as they are generated conditioning only on information available at the time the forecast is being made. ${ }^{6}$ The forecasting performance metrics are the root mean square error (RMSE) and mean absolute deviation (MAD).

Table 4 reports the relative multi-step-ahead ex-ante predictive performance of the competing modeling strategies, in the form of normalized forecasting metrics with respect to the AR model, for the simple sum monetary series. A value less than unity implies that the fractional model provides more accurate forecasts than the AR model for the horizon in question. The percentage reductions in the forecasting accuracy criteria (RMSE and MAE) attained by the fractional model are rather sizeable for the simple sum M1, M2, and L series. In most cases, the superiority of the fractional forecasts is robust to the forecasting

\footnotetext{
4 In specifying the lag length for the linear AR model, we follow the same procedure as for the choice of the short-memory (AR) order of the fractional model.

5 We maintain a validation set of adequate size in order to effectively compare the out-of-sample accuracy of competing forecasts for all prediction horizons.

6 See Lardic and Mignon (1996) for arguments on the comparative performance of fractional forecasts over short- and longer-term horizons.
} 
horizon. However, the AR forecasts dominate the fractional forecasts for the simple sum M3 aggregate. Similar evidence is obtained for the divisia forecasts, as shown in Table 5. The fractional forecasts provide accuracy gains compared to the AR counterparts for the DM1, DM2, and DL series but the evidence is weak and mixed for the DM3 series.

Overall, the results of our forecasting experiment can be summarized as follows:

i) Out-of-sample fractional forecasts result in rather sizeable improvements over AR forecasts for most of the monetary aggregates,

ii) Such forecasting gains are robust with respect to the length of forecasting horizon, and

iii) Such forecasting gains are consistent across forecasting metrics used (the fractional model "wins" based on both RMSE and MAD measures). ${ }^{7}$

While the forecasting improvements appear sizeable in most cases, it might be premature to declare victory as there is no assurance that they are statistically significant. To test the equality of forecast accuracy between the competing models, we employ the test proposed by Diebold and Mariano (DM, 1995), which can easily be applied to a wide variety of criteria including RMSE and MAD. Given two forecast errors $\left\{\varepsilon_{i t}\right\}_{t=1}^{T}$ and $\left\{\varepsilon_{j t}\right\}_{t=1}^{\zeta}$, the $D M$ statistic is defined as

\footnotetext{
7 As a long-memory process can be approximated by an AR $(p)$ process with a large order $p$, we also produced out-of-sample forecasts using an AR model of long order, AR(30), in an attempt to capture the persistence of the series without modeling it as a long-memory process. The AR(30) forecasts are inferior to the ARFIMA forecasts for all simple sum indices (except the SL series) and for all divisia series. Therefore the long-autoregression forecasts do not appear to be particularly useful in this instance. These results are available upon request.
} 


$$
D M=\frac{\bar{s}}{\sqrt{\frac{2 \pi \hat{f}_{S}(0)}{T}}}
$$

where $\bar{s}=\frac{1}{T} \sum_{t=1}^{T}\left[g\left(\varepsilon_{i t}\right)-g\left(\varepsilon_{j t}\right)_{-}^{-}\right.$is the sample mean loss differential and $\hat{f}_{s}(0)$ is a consistent estimate of the spectral density of the loss differential at frequency 0 , $f_{S}(0)$. A consistent estimator of $2 \pi f_{S}(0)$ is obtained by taking a two-sided weighted sum of the available sample autocovariances

$$
2 \pi \hat{f}_{S}(0)=\sum_{\tau=-(T-1)}^{T-1} 1\left(\frac{\tau}{S(T)}\right) \hat{\gamma}_{S}(\tau)
$$

where $\hat{\gamma}_{S}(\tau)$ is the sample autocovariance at displacement $\tau, 1\left(\frac{\tau}{S(T)}\right)$ is the lag window, and $S(T)$ is the truncation lag. Uniform or Bartlett lag windows and several truncation lags can be considered. The $D M$ statistic is asymptotically $t$-distributed and accommodates non-Gaussian, nonzero mean, serially correlated, and contemporaneously correlated forecast errors.

As shown in Tables 3 and 4, only sporadically is the null hypothesis of equal forecasting accuracy (in RMSE and MAD) by the ARFIMA and AR forecasts rejected by the $D M$ test. Even though the fractional forecasts result in rather sizeable forecasting improvements over the benchmark forecasts, such superiority is not generally statistically significant. 
We also employ the forecasting encompassing testing approach for our competing forecasts suggested by Clements and Hendry (1998). Let 1=ARFIMA model, $2=$ AR model, $E_{i}=$ forecast error for model $i=1,2$, and $D=$ the difference between the forecasts from the two models. The forecast encompassing test is based on running two regressions: the first involves regressing the forecast error from the ARFIMA model on the difference of forecasts, i.e., $E_{1, t}=\alpha_{1}+\beta_{1} D_{t}+\varepsilon_{1, t}$, and the second involves the regression $E_{2, t}=\alpha_{2}+\beta_{2} D_{t}+\varepsilon 2, t$.

If $\hat{\beta}_{1}\left(\hat{\beta}_{2}\right)$ is not statistically significant and $\hat{\beta}_{2}\left(\hat{\beta}_{1}\right)$ is, the null hypothesis that neither model encompasses the other is rejected in favor of the alternative that the ARFIMA (AR) model encompasses the AR (ARFIMA) model. If both $\hat{\beta}_{1}$ and $\hat{\beta}_{2}$ are statistically significant, or if both are insignificant, then we fail to reject the null that neither model encompasses the other. The cut-off point for statistical significance is a significance level less than 5 per cent for the $t$-statistics of the estimated slope coefficients.

Table 5 presents the forecast encompassing tests for the simple sum series. Only rarely is the null hypothesis that neither model encompasses the other rejected in favor of either ARFIMA or AR forecast encompassing superiority. The overall evidence therefore suggests neither model is superior to the other in terms of forecast encompassing.

The forecast encompassing tests provide sharper results for the divisia indices. As Table 6 reports, for the DM1, DM2, and DL money measures and for virtually all forecasting horizons, the null hypothesis that neither model encompasses the other is rejected in favor of the alternative that the ARFIMA 
model encompasses the AR model ( $\hat{\beta}_{2}$ is statistically significant and $\hat{\beta}_{1}$ is not). Only in two cases for the DM1 series is the null hypothesis rejected in favor of the alternative that the AR model encompasses the ARFIMA one. The evidence overwhelmingly implies that in those cases where the AR model fails to forecast the monetary series correctly, such failure can be accounted for by the ARFIMA model. Additionally, in those cases where the ARFIMA model fails to correctly forecast the divisia series, such failure cannot be accounted for by the AR model. The conclusion is that the ARFIMA model can explain the forecast error of the linear model but not vice versa. For the DM3 series, the majority of the evidence suggests that neither model encompasses the other.

\section{Conclusions}

We demonstrated that simple sum and divisia monetary aggregates are fractional processes with an integration order between one and two. We also generated out-of-sample fractional forecasts and showed that, for most monetary aggregates, they provide more accurate point predictions of the conditional mean relative to autoregressive forecasts for different prediction horizons. However, the forecasting improvements are not statistically significant in general. The forecast encompassing test results suggest that the fractional model encompasses the autoregressive model for the divisia series, but the two models have broadly similar power for the simple sum series. With the possible exception of the M3 series, rarely is the fractional model inferior to the AR model in terms of forecast effectiveness. This evidence is encouraging and suggestive of the potential usefulness of nonlinear fractional forecasts for monetary series. 


\section{References}

Baillie RT, Chung CF, Tieslau MA. 1996. Analysing inflation by the fractionally integrated ARFIMA-GARCH model. Journal of Applied Econometrics 11: 2340.

Barkoulas JT, Baum CF. 1997. Fractional differencing modeling and forecasting of eurocurrency deposit rates. Journal of Financial Research 20(3): 355-372.

Barkoulas JT, Baum CF, Caglayan M. 1999. Fractional Monetary Dynamics. Applied Economics 31: 1393-1400.

Baum CF, Barkoulas JT, Caglayan M. 1999. Persistence in international inflation rates. Southern Economic Journal 65: 900-913.

Cheung YW. 1993. Long memory in foreign-exchange rates. Journal of Business and Economic Statistics 11: 93-101.

Clements M, Hendry D. 1998. Forecasting economic time series. Cambridge University Press: Cambridge UK.

Crato N, Ray B. 1996. Model selection and forecasting for long-range dependent processes. Journal of Forecasting 15: 107-125.

Diebold FX, Lindner P. 1996. Fractional integration and interval prediction. Economics Letters 50: 305-313.

Diebold FX, Mariano R. 1995. Comparing predictive accuracy. Journal of Business and Economic Statistics 13: 253-263.

Diebold FX, Rudebusch GD. 1989. Long memory and persistence in aggregate output. Journal of Monetary Economics 24: 189-209.

Diebold FX, Rudebusch GD. 1991. Is consumption too smooth? Long memory and the Deaton paradox. Review of Economics and Statistics 71: 1-9. 
Fildes R, Stekler H. 2002. The state of macroeconomic forecasting. Journal of Macroeconomics 24: 435-468.

Franses PH, Ooms M. 1997. A periodic long-memory model for quarterly UK inflation. International Journal of Forecasting 13: 117-126.

Geweke J, Porter-Hudak S. 1983. The estimation and application of long memory time series models. Journal of Time Series Analysis 4: 221-238.

Granger CWJ, Joyeux R. 1980. An introduction to long-memory time series models and fractional differencing. Journal of Time Series Analysis 1: 15-39.

Guegman D. 1994. Series chronologiques non-lineaires a temps discret. Economica: Paris.

Hassler U, Wolters J. 1995. Long memory in inflation rates: International evidence. Journal of Business and Economic Statistics 13: 37-45.

Hosking JRM 1981. Fractional Differencing. Biometrika 68: 165-176.

Lardic S, Mignon V. 1996. ARFIMA predictions of foreign exchange rates: Does one still exhort to naïve forecasts? In Proceedings of "Theorie et methods de la macroeconomie" Symposium, Paris, France.

Porter-Hudak S. 1990. An application of the seasonal fractionally differenced model to the monetary aggregates. Journal of the American Statistical Association 85: 338-344.

Ray B. 1993a. Modeling long-memory processes for optimal long-range prediction. Journal of Time Series Analysis 14: 511-525.

Ray B. 1993b. Long range forecasting of IBM product revenues using a seasonal fractionally differenced ARMA model. International Journal of Forecasting 9: 255-269. 
Robinson P. 1995a. Gaussian semiparametric estimation of long range dependence. Annals of Statistics 13: 1630-1661.

Robinson P. 1995b. Log-periodogram regression of time series with long range dependence. Annals of Statistics 23: 1048-1072.

Sowell F. 1992. Modeling long-run behavior with the fractional ARIMA model. Journal of Monetary Economics 29: 277-302.

Wright JH. 1995. Stochastic orders of magnitude associated with two-stage estimators of fractional ARIMA systems. Journal of Time Series Analysis 16: $119-125$. 
Table 1: Estimates of the Fractional Differencing Parameter for the U.S. Monetary Indices

\begin{tabular}{|c|c|c|c|c|c|}
\hline \multirow[t]{2}{*}{ Series } & \multicolumn{5}{|c|}{ Gaussian Semiparametric Estimates } \\
\hline & $d(0.50)$ & $d(0.525)$ & $d(0.55)$ & $d(0.575)$ & $d(0.60)$ \\
\hline \multicolumn{6}{|c|}{ Part A: Simple Sum } \\
\hline SM1 & $\begin{array}{c}0.441 \\
(3.844)^{*}\end{array}$ & $\begin{array}{c}0.405 \\
(3.799)^{*}\end{array}$ & $\begin{array}{c}0.332 \\
(3.385)^{*}\end{array}$ & $\begin{array}{c}0.340 \\
(3.724)^{*}\end{array}$ & $\begin{array}{c}0.410 \\
(4.851)^{*}\end{array}$ \\
\hline SM2 & $\begin{array}{c}0.388 \\
(3.382)^{*}\end{array}$ & $\begin{array}{c}0.336 \\
(3.151)^{*}\end{array}$ & $\begin{array}{c}0.307 \\
(3.130)^{*}\end{array}$ & $\begin{array}{c}0.330 \\
(3.614)^{*}\end{array}$ & $\begin{array}{c}0.375 \\
(4.437)^{*}\end{array}$ \\
\hline SM3 & $\begin{array}{c}0.459 \\
(4.001)^{*}\end{array}$ & $\begin{array}{c}0.502 \\
(4.709)^{*}\end{array}$ & $\begin{array}{c}0.496 \\
(5.058)^{*}\end{array}$ & $\begin{array}{c}0.513 \\
(5.619)^{*}\end{array}$ & $\begin{array}{c}0.548 \\
(6.484)^{*}\end{array}$ \\
\hline SL & $\begin{array}{c}0.555 \\
(4.838)^{*}\end{array}$ & $\begin{array}{c}0.609 \\
(5.712)^{*}\end{array}$ & $\begin{array}{c}0.529 \\
(5.394)^{*}\end{array}$ & $\begin{array}{c}0.524 \\
(5.740)^{*}\end{array}$ & $\begin{array}{c}0.539 \\
(6.377)^{*}\end{array}$ \\
\hline \multicolumn{6}{|c|}{ Part B: Divisia } \\
\hline DM1 & $\begin{array}{c}0.458 \\
(3.992)^{*}\end{array}$ & $\begin{array}{c}0.424 \\
(3.977)^{*}\end{array}$ & $\begin{array}{c}0.353 \\
(3.599)^{*}\end{array}$ & $\begin{array}{c}0.367 \\
(4.020)^{*}\end{array}$ & $\begin{array}{c}0.406 \\
(4.803)^{*}\end{array}$ \\
\hline DM2 & $\begin{array}{c}0.427 \\
(3.722)^{*}\end{array}$ & $\begin{array}{c}0.379 \\
(3.555)^{*}\end{array}$ & $\begin{array}{c}0.342 \\
(3.487)^{*}\end{array}$ & $\begin{array}{c}0.394 \\
(4.316)^{*}\end{array}$ & $\begin{array}{c}0.445 \\
(5.265)^{*}\end{array}$ \\
\hline DM3 & $\begin{array}{c}0.379 \\
(3.304)^{*}\end{array}$ & $\begin{array}{c}0.410 \\
(3.846)^{*}\end{array}$ & $\begin{array}{c}0.400 \\
(4.079)^{*}\end{array}$ & $\begin{array}{c}0.459 \\
(5.028)^{*}\end{array}$ & $\begin{array}{c}0.513 \\
(6.069)^{*}\end{array}$ \\
\hline DL & $\begin{array}{c}0.400 \\
(3.487)^{*}\end{array}$ & $\begin{array}{c}0.436 \\
(4.090)^{*}\end{array}$ & $\begin{array}{c}0.433 \\
(4.415)^{*}\end{array}$ & $\begin{array}{c}0.487 \\
(5.334)^{*}\end{array}$ & $\begin{array}{c}0.506 \\
(5.987)^{*}\end{array}$ \\
\hline
\end{tabular}

Notes: The data cover the in-sample period 1959:1-1990:12 for a total of 384 monthly observations (the remainder of the sample is reserved for out-of-sample forecasting purposes). All series are expressed in growth rates (first logarithmic differences of the level series). $d(0.50)$, $d(0.525), d(0.55), d(0.575)$, and $d(0.60)$ correspond to estimation sample size (number of Fourier frequencies) $v=T^{0.50}, v=T^{0.525}, v=T^{0.55}, v=T^{0.575}$, and $v=T^{0.60}$, respectively. The $t$-statistics are given in parentheses. The superscript * indicates statistical significance for the null hypothesis $d=0$ against the alternative $d \neq 0$ at the 1 per cent level. 
Table 2: Robinson Multivariate Log-periodogram Regression for the U.S. Monetary Indices

\begin{tabular}{|c|c|c|c|c|c|}
\hline \multirow[t]{2}{*}{ Series } & \multicolumn{5}{|c|}{ Robinson Multivariate Estimates } \\
\hline & $d(0.60)$ & $d(0.65)$ & $d(0.70)$ & $d(0.75)$ & $d(0.80)$ \\
\hline \multicolumn{6}{|l|}{ Part A: Simple Sum } \\
\hline SM1 & $\begin{array}{c}0.466 \\
(4.166)^{*}\end{array}$ & $\begin{array}{c}0.392 \\
(4.078)^{*}\end{array}$ & $\begin{array}{c}0.335 \\
(3.668)^{*}\end{array}$ & $\begin{array}{c}0.298 \\
(3.930)^{*}\end{array}$ & $\begin{array}{c}0.285 \\
(4.479)^{*}\end{array}$ \\
\hline SM2 & $\begin{array}{c}0.352 \\
(3.150)^{*}\end{array}$ & $\begin{array}{c}0.366 \\
(3.808)^{*}\end{array}$ & $\begin{array}{c}0.494 \\
(5.404)^{*}\end{array}$ & $\begin{array}{c}0.415 \\
(5.466)^{*}\end{array}$ & $\begin{array}{c}0.482 \\
(7.571)^{*}\end{array}$ \\
\hline SM3 & $\begin{array}{c}0.628 \\
(5.609)^{*}\end{array}$ & $\begin{array}{c}0.622 \\
(6.476)^{*}\end{array}$ & $\begin{array}{c}0.668 \\
(7.317)^{*}\end{array}$ & $\begin{array}{c}0.533 \\
(7.014)^{*}\end{array}$ & $\begin{array}{c}0.523 \\
(8.205)^{*}\end{array}$ \\
\hline SL & $\begin{array}{c}0.553 \\
(4.940)^{*}\end{array}$ & $\begin{array}{c}0.486 \\
(5.064)^{*}\end{array}$ & $\begin{array}{c}0.657 \\
(7.191)^{*}\end{array}$ & $\begin{array}{c}0.504 \\
(6.638)^{*}\end{array}$ & $\begin{array}{c}0.440 \\
(6.901)^{*}\end{array}$ \\
\hline $\begin{array}{l}F \text { Test } \\
\text { (Panel:SM1, SM2, SM3, SL) }\end{array}$ & $\begin{array}{c}1.457 \\
(0.344) \\
\end{array}$ & $\begin{array}{l}1.457 \\
(0.227) \\
\end{array}$ & $\begin{array}{l}2.966 \\
(0.032) \\
\end{array}$ & $\begin{array}{l}1.926 \\
(0.124)\end{array}$ & $\begin{array}{l}2.655 \\
(0.048) \\
\end{array}$ \\
\hline $\begin{array}{l}F \text { Test } \\
\text { (Panel: SM2, SM3, SL) }\end{array}$ & $\begin{array}{l}1.597 \\
(0.207) \\
\end{array}$ & $\begin{array}{c}1.779 \\
(0.172) \\
\end{array}$ & $\begin{array}{c}1.077 \\
(0.342) \\
\end{array}$ & $\begin{array}{c}0.628 \\
(0.534) \\
\end{array}$ & $\begin{array}{c}0.400 \\
(0.670) \\
\end{array}$ \\
\hline Part B: Divisia & & & & & \\
\hline DM1 & $\begin{array}{c}0.424 \\
(3.914)^{*}\end{array}$ & $\begin{array}{c}0.348 \\
(3.681)^{*} \\
\end{array}$ & $\begin{array}{c}0.267 \\
(3.516)^{*}\end{array}$ & $\begin{array}{c}0.243 \\
(3.605)^{*} \\
\end{array}$ & $\begin{array}{c}0.237 \\
(4.249)^{*}\end{array}$ \\
\hline DM2 & $\begin{array}{c}0.557 \\
(5.138)^{*}\end{array}$ & $\begin{array}{c}0.478 \\
(5.063)^{*}\end{array}$ & $\begin{array}{c}0.507 \\
(6.662)^{*}\end{array}$ & $\begin{array}{c}0.473 \\
(7.012)^{*}\end{array}$ & $\begin{array}{c}0.482 \\
(8.621)^{*}\end{array}$ \\
\hline DM3 & $\begin{array}{c}0.558 \\
(5.147)^{*}\end{array}$ & $\begin{array}{c}0.553 \\
(5.853)^{*}\end{array}$ & $\begin{array}{c}0.576 \\
(7.567)^{*} \\
\end{array}$ & $\begin{array}{c}0.585 \\
(8.671)^{*} \\
\end{array}$ & $\begin{array}{c}0.561 \\
(10.037)^{*}\end{array}$ \\
\hline DL & $\begin{array}{c}0.485 \\
(4.480)^{*} \\
\end{array}$ & $\begin{array}{c}0.497 \\
(5.261)^{*}\end{array}$ & $\begin{array}{c}0.543 \\
(7.136)^{*} \\
\end{array}$ & $\begin{array}{c}0.587 \\
(8.694)^{*} \\
\end{array}$ & $\begin{array}{c}0.613 \\
(10.961)^{*}\end{array}$ \\
\hline $\begin{array}{l}F \text { Test } \\
\text { (Panel:DM1, DM2, DM3, DL) }\end{array}$ & $\begin{array}{c}0.351 \\
(0.788)\end{array}$ & $\begin{array}{l}0.844 \\
(0.471)\end{array}$ & $\begin{array}{c}3.387 \\
(0.018) \\
\end{array}$ & $\begin{array}{c}5.728 \\
(0.000) \\
\end{array}$ & $\begin{array}{c}8.832 \\
(0.000)\end{array}$ \\
\hline $\begin{array}{l}F \text { Test } \\
\text { (Panel: DM2, DM3, DL) }\end{array}$ & $\begin{array}{c}0.172 \\
(0.842)\end{array}$ & $\begin{array}{c}0.197 \\
(0.821)\end{array}$ & $\begin{array}{c}0.240 \\
(0.786)\end{array}$ & $\begin{array}{l}1.048 \\
(0.352)\end{array}$ & $\begin{array}{c}1.492 \\
(0.226)\end{array}$ \\
\hline
\end{tabular}

Notes: See notes in Table 1 for data and notation details. The Robinson multivariate test is applied to the growth rates (first logarithmic differences) of the series. The $t$-statistics are given in parentheses below the coefficient estimates. $F$ test is a test of the equality of $d$ estimates for the panel series and its $p$-value is given in parentheses. The superscript ${ }^{*}$ indicates statistical significance for the null hypothesis $d=0$ against the alternative $d \neq 0$ at the 1 per cent level. 


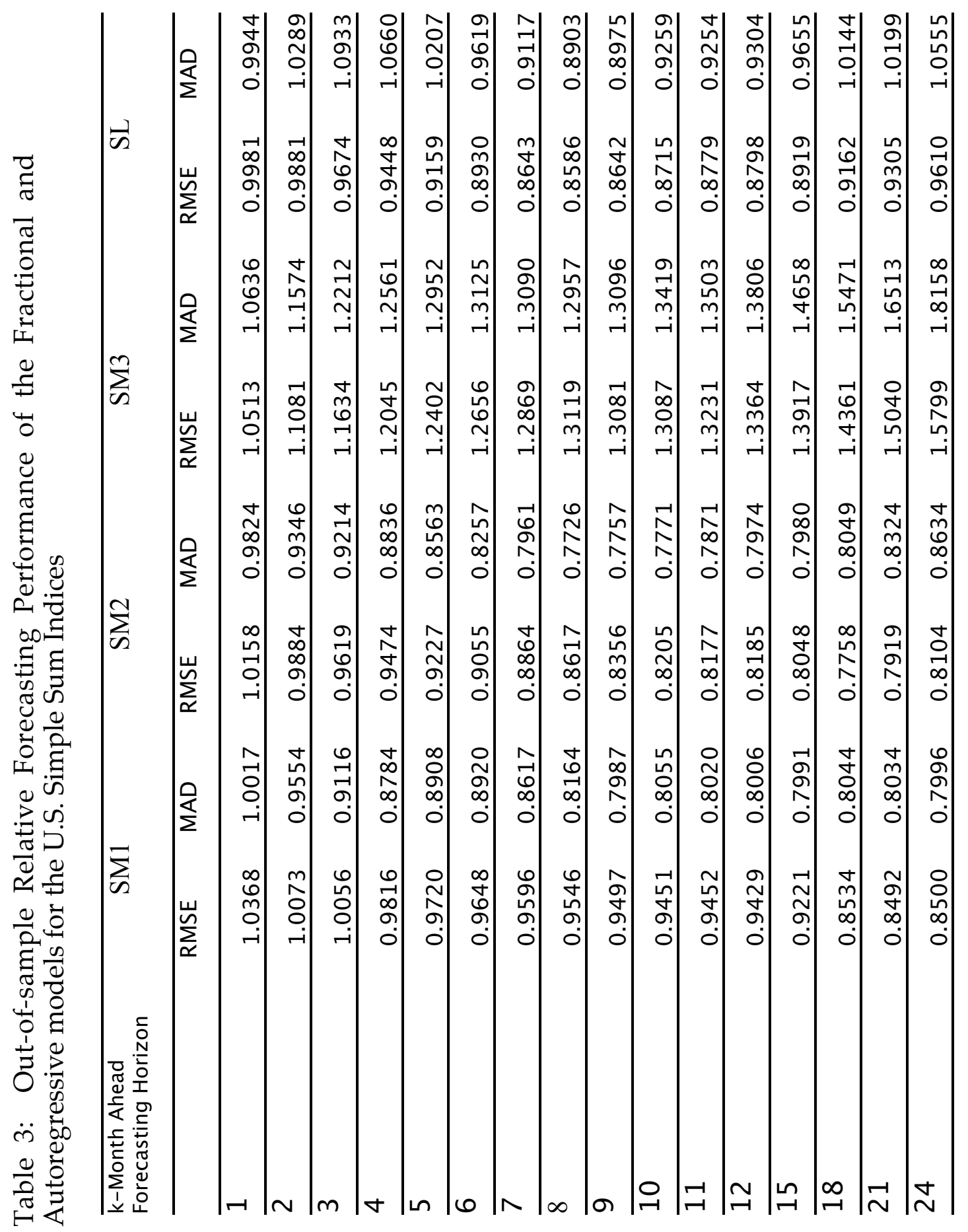




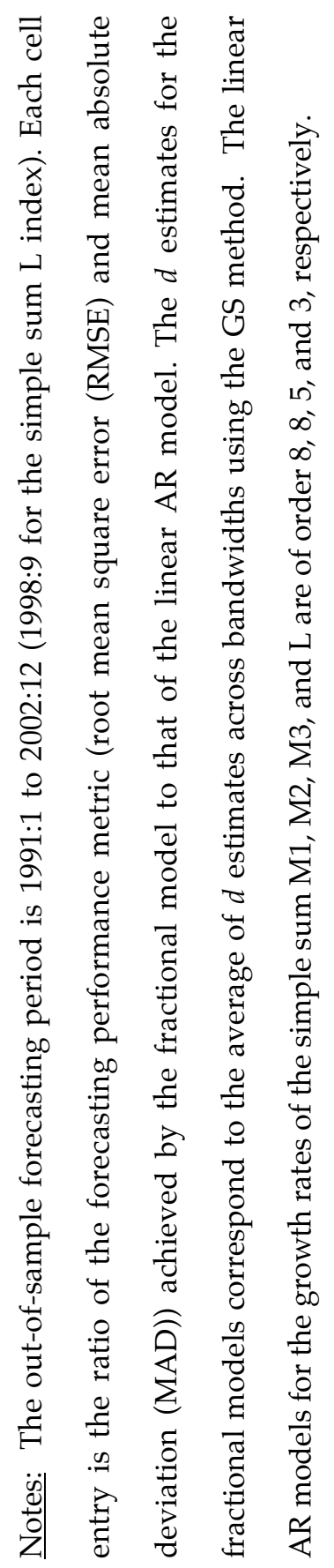




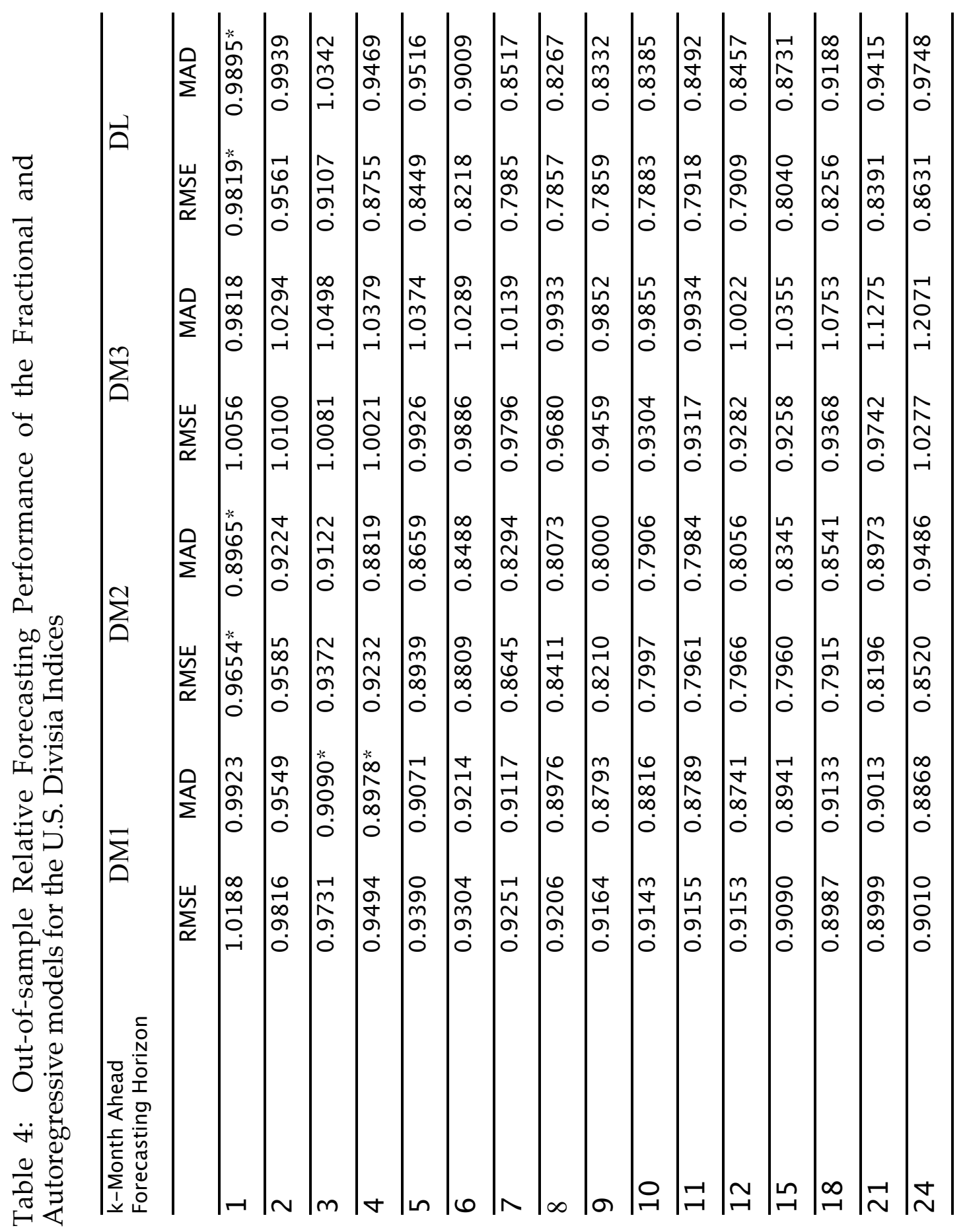




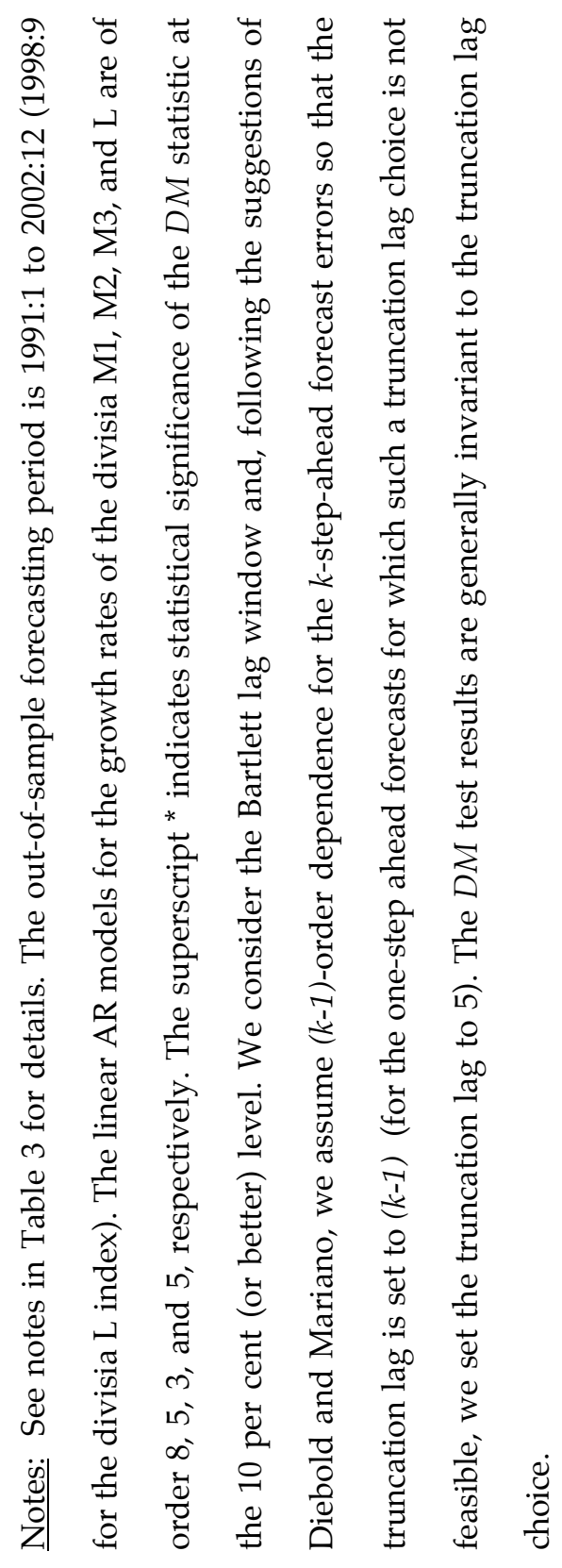




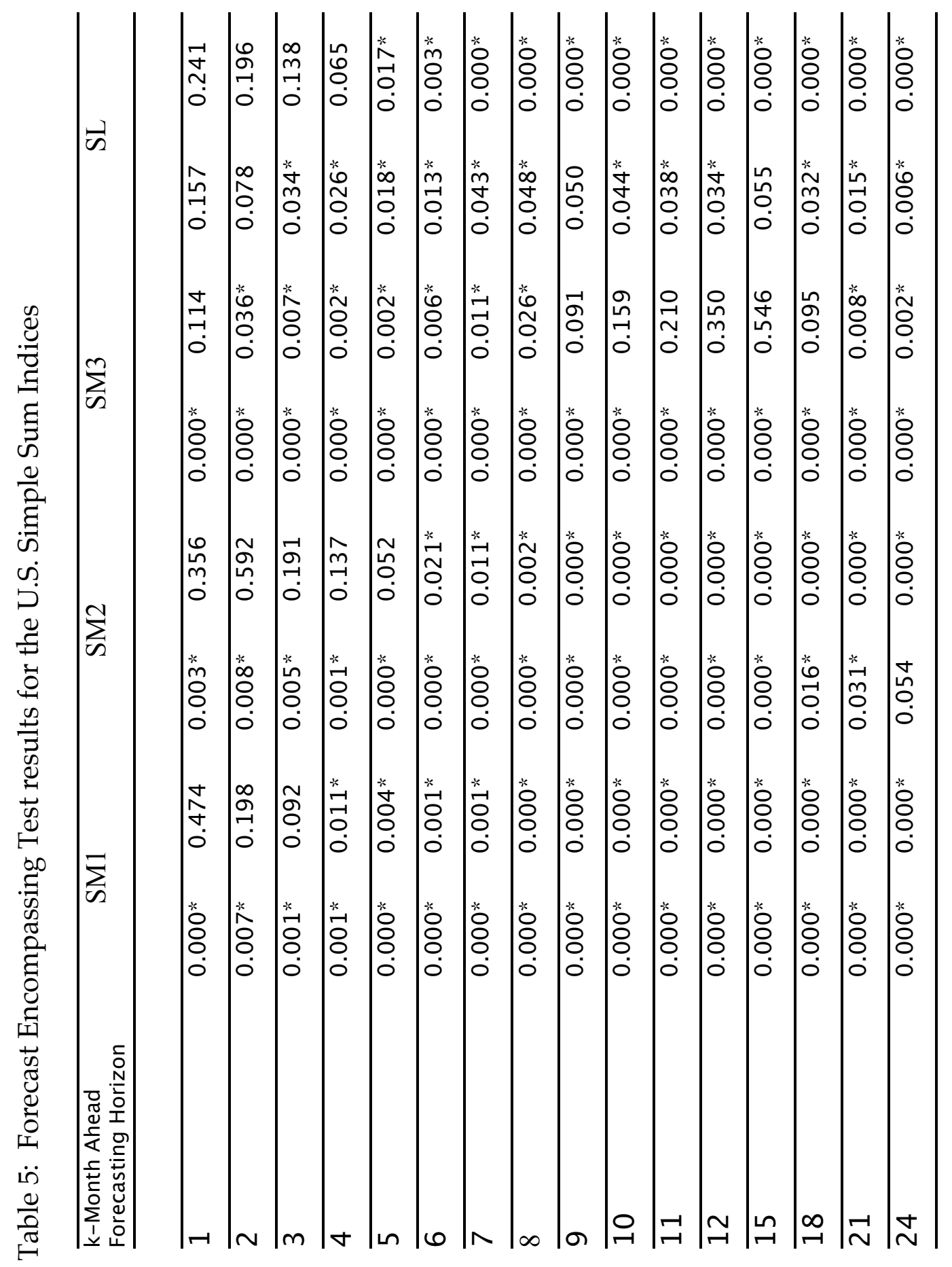




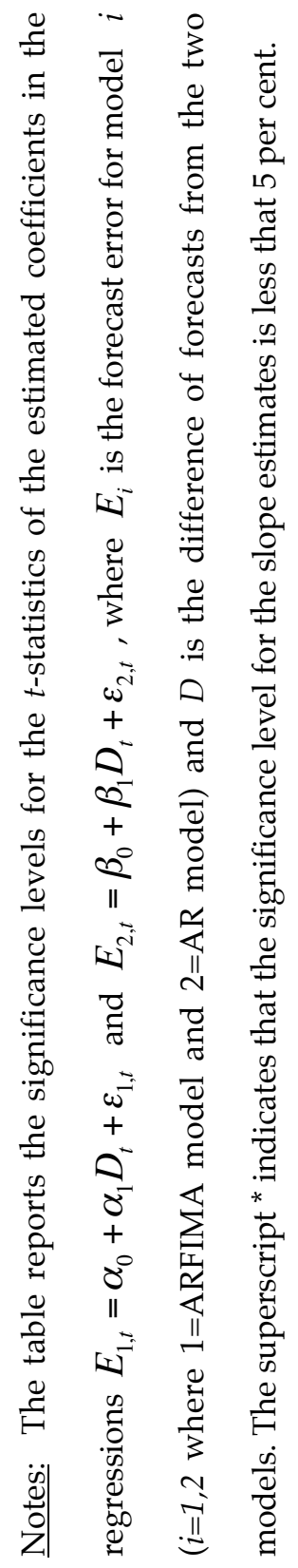




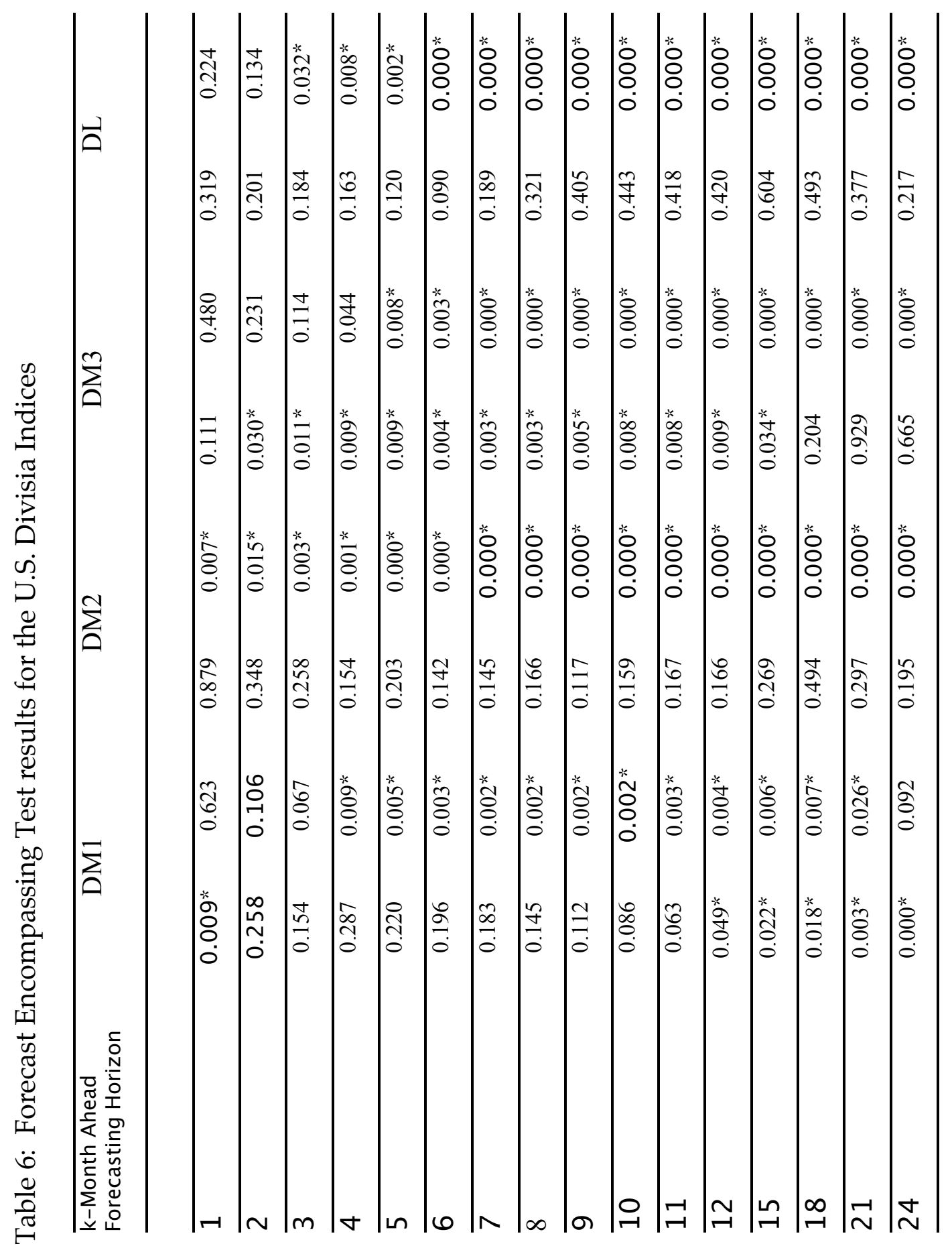




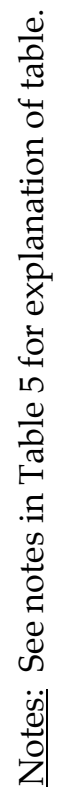


Figure 1. Empirical autocorrelations

Growth rates of simple-sum series

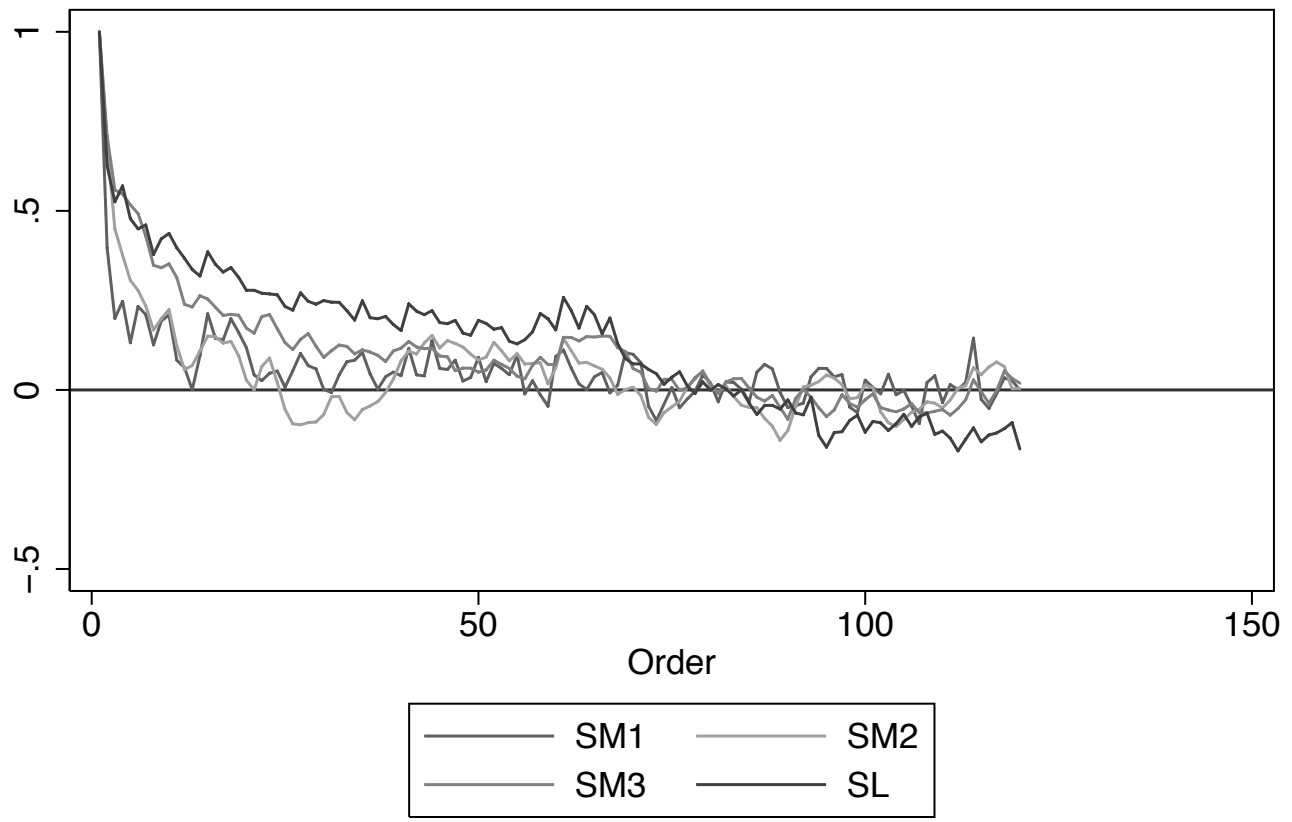


Figure 2. Empirical autocorrelations

Growth rates of divisia series

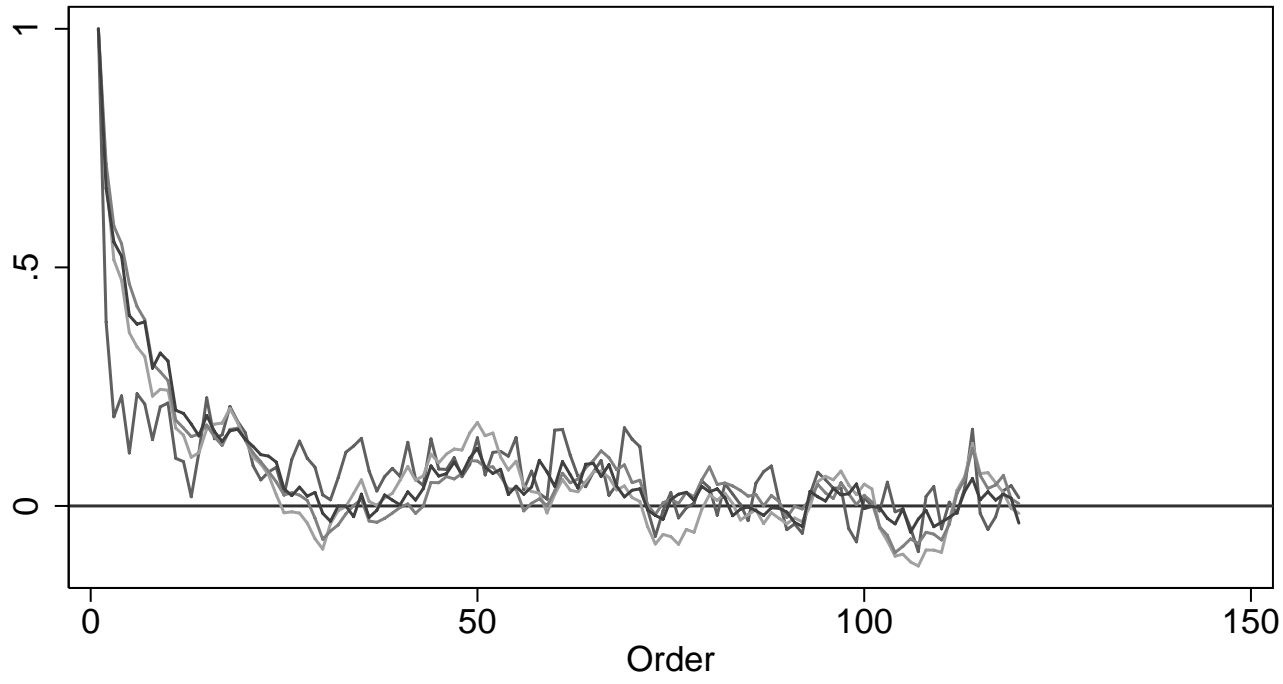

$\begin{array}{ll}\mathrm{DM} 1 & \mathrm{DM} 2 \\ \mathrm{DM} 3 & \mathrm{DL}\end{array}$

